\title{
EFEITOS DO EXTRATO DO CAROÇO DO ABACATE SOBRE A INFLAMAÇÃO INDUZIDA NA PATA DE RATOS PELA CARRAGENINA
}

\author{
Giuliano Roberto da Silva \\ Docente da Faculdade Presbiteriana Gammon-Lavras-MG \\ Docente da UNIFENAS - Alfenas-MG \\ Docente da UNINCOR - Três Corações-MG \\ Graduada em Educação Física pela FAGAMMON-Lavras-MG \\ Pós graduada em Ginástica Especial Corretiva - UNIFMU-SP \\ e em Diversidade e Gênero na Escola - UFLA e UAB-MG \\ Mestre em Biotecnologia em Saúde - UNINCOR-MG \\ Doutorado em andamento em Promoção de Saúde na Universidade de Franca-SP \\ e-mail: giumusc@gmail.com \\ Dr. Tufi Neder Meyer \\ Mestre e Doutor em Cirurgia pela Faculdade de Medicina da UFMG \\ Docente Orientador do Mestrado em Biotecnologia/Odontologia da UNINCOR - Três Corações-MG \\ Dra Joana Beatriz de Barros Pereira \\ Mestre e Doutora em Educação pela UNINCOR-Três Corações-MG \\ Docente Co-orientadora do Mestrado em Biotecnologia em Saúde da UNINCOR-Três Corações-MG
}

Recebido em: 04/07/2014 Aprovado em: 15/09/2014

\begin{abstract}
RESUMO
O abacate é uma fruta abundante no território nacional. Há relatos etnofarmacológicos do uso de extratos do caroço do abacate nas contusões musculares. Neste trabalho, foram estudados os efeitos do extrato hidroalcóolico do caroço do abacate a $80 \%$ sobre o processo inflamatório em um modelo experimental utilizando ratos Wistar. Foram usados 25 ratos adultos machos, divididos em 5 grupos de 5 animais cada. Em todos os grupos, foi induzida inflamação pela injeção, na almofada plantar de pata traseira direita, de solução de carragenina $0,1 \%$. Além da carragenina, em cada grupo ocorreram os seguintes tratamentos, ministrados por via oral (gavagem): grupo 1 solução de cloreto de sódio a $0,9 \%$; grupo 2 - piroxicam $50 \mathrm{mg} / \mathrm{Kg}$; grupo 3 - extrato do caroço de abacate, dose de $0,5 \mathrm{~mL} / \mathrm{kg}$; grupo 4 - extrato do caroço de abacate, 1,5 $\mathrm{mL} / \mathrm{kg}$; grupo 5 - extrato do caroço de abacate, $2,0 \mathrm{~mL} / \mathrm{kg}$. A evolução do edema foi acompanhada 1, 2, 3 e 4 horas após o início dos tratamentos. As medições do volume da pata foram feitas por um sistema em que uma seringa plástica de $10 \mathrm{~mL}$, contendo água, serviu para quantificar o volume de líquido deslocado pela imersão da pata tratada. Os animais foram mortos por transecção medular após o término dos experimentos. Os resultados foram tabulados, analisados e submetidos a tratamento estatístico. Não foram observadas diferenças significativas entre os grupos de tratamentos. Nesse experimento, não foram constatados efeitos anti-inflamatórios do extrato do caroço do abacate.
\end{abstract}

Palavras-chave: Plantas medicinais. Inflamação. Anti-inflamatórios. 


\title{
EFFECTS OF EXTRACTS OF AVOCADO SEEDS ON INFLAMMATION INDUCED IN RAT'S FOOT BY CARRAGEENAN
}

\begin{abstract}
Avocado is a widespread fruit in Brazil. There are ethnopharmacological reports about the use of extracts of avocado seed to treat muscle contusions. In this work, studies were performed to evaluate effects of $80 \%$ avocado seed extract on inflammation in an experimental model using Wistar rats. 25 adults, male rats were divided into 5 groups of 5 animals each. In all groups, inflammation was induced through subcutaneous plantar hindpaw injection of $0.1 \%$ carragenin $(0.1 \mathrm{~mL})$. Besides carragenin, in each group the following treatments were administered through gavage: group $1-0.9 \%$ sodium chloride solution; group 2 - piroxicam, $50 \mathrm{mg} / \mathrm{Kg}$; group 3 - avocado seed extract, 0.5 $\mathrm{mL} / \mathrm{kg}$; group 4 - avocado seed extract, $1.5 \mathrm{~mL} / \mathrm{kg}$; group 5 - avocado seed extract, 2.0 $\mathrm{mL} / \mathrm{kg}$. Edema evolution was evaluated 1, 2, 3 and 4 hours after the onset of treatments. Paw volume measurements were performed by means of a system in which a $10-\mathrm{mL}$ plastic syring, containing water, allowed quantification of the liquid volume dislocated by the immersion of the treated paw. The animals were killed, after experiments ended, by medullary transection. The results were tabulated, analysed and statistically treated. No differences in results were observed among the treatment groups. In this experiment, no anti-inflammatory effects of avocado seed extract were observed.
\end{abstract}

Keywords: Medicinal plants. Inflammation. Anti-inflammatory.

\section{INTRODUÇÃ̃}

O mundo vem passando por transformações de diversas ordens e aspectos e vamos ressaltar o modo de vida estressante e sedentário da população moderna atual. Alterações significativas, tanto no âmbito biológico como no psicológico e no social são observadas. No âmbito biológico, destacam-se as lesões musculares, que acometem a população em geral (LIMA, 2005).

Quando acontece uma lesão, as pessoas são levadas a procurar diversos meios de tratamento: uso de medicamentos sintetizados (com todos os seus efeitos colaterais), plantas medicinais e tratamentos não medicamentosos (fisioterapia, exercícios, alongamentos, reeducação postural, Pilates) (GOLDENBERG, 2005; RIO DE JANEIRO, 2002).

De acordo com a World Health Organization (1946), o uso inadequado dos princípios ativos, seja de medicamentos sintetizados, seja de plantas medicinais, coloca a pessoa em várias situações de risco, entre elas: retardo do reconhecimento da doença, 
com a possibilidade de agravamento do quadro; diagnóstico incorreto; escolha de uma terapia inadequada e até mesmo tornar-se dependente da droga contida nesse medicamento.

O caroço do abacate é utilizado pela população nas contusões musculares, caracterizando seu uso etnofarmacológico (LORENZI, 2002). Em vista disso, é útil investigar se realmente essa matéria prima, abundante no território nacional, barata e de fácil obtenção, apresenta os referidos efeitos terapêuticos. Se comprovadas sua eficiência anti-inflamatória e ausência ou pouca incidência de efeitos colaterais, poderá ser utilizada corretamente sem maior risco à saúde da população. Isso pode levar ao achado de novos fármacos de interesse terapêutico. Esses procedimentos são controlados em legislação específica (ANVISA, 2006).

Este trabalho teve como objetivo avaliar os efeitos do extrato hidroetanólico do caroço de abacate sobre o edema induzido pela carragenina na pata traseira de ratos.

\section{REFERENCIAL TEÓRICO}

\subsection{Plantas medicinais e uso nas comunidades}

O uso de plantas medicinais, como prática alternativa aos tratamentos ortodoxos, pode contribuir para a saúde dos indivíduos, mas deve ser parte de um sistema integral que torne a pessoa realmente saudável e não simplesmente sem doença (DI STASI, 1996).

O uso de plantas medicinais pela população mundial tem sido muito significativo nos últimos tempos. Dados da OMS mostram que cerca de $80 \%$ da população mundial fez uso de algum tipo de planta medicinal na busca de alívio de algum sintoma doloroso ou desagradável. Desse total, pelo menos $30 \%$ deu-se por indicação médica. A utilização de plantas medicinais tem recebido incentivo da própria OMS. São muitos os fatores que vêm colaborando no desenvolvimento de práticas de saúde que incluam plantas medicinais, principalmente econômicos e sociais (CORREA et al., 1991).

No Brasil, o consumo de fitoterápicos tem aumentado mais que aquele dos medicamentos sintéticos. Acredita-se que o uso de plantas medicinais pode reduzir à 
metade os gastos da população com medicamentos e, hipoteticamente, com os mesmos resultados dos produtos alopáticos (ABIF, 2007).

No século XIX, Von Martius teria dito que "as plantas medicinais brasileiras não curam apenas, elas fazem milagres". Com essa célebre frase ele definiu muito bem a capacidade das plantas medicinais do país. É bem provável que das 200 mil espécies vegetais que possam existir no Brasil, pelo menos a metade pode ter alguma propriedade terapêutica útil à população. Entretanto, nem $1 \%$ dessas espécies já foi motivo de estudos adequados. Os trabalhos de pesquisa com plantas medicinais originam medicamentos em menor tempo, com custos muitas vezes inferiores e, consequentemente, mais acessíveis à população (GUIMARÃES, 2000).

As plantas medicinais que têm avaliadas a sua eficiência terapêutica e a toxicologia ou segurança de uso estão cientificamente aprovadas para serem utilizadas pela população nas suas necessidades básicas de saúde. Uma vez que as plantas medicinais são classificadas como produtos naturais, a lei permite que sejam comercializadas livremente. Com isso, a automedicação é facilitada nos casos considerados mais simples e corriqueiros, o que reduz a procura pelos profissionais da saúde, facilitando e reduzindo o custo do serviço de saúde pública. Por essas razões é que trabalhos de difusão e resgate do conhecimento de plantas vêm-se difundindo cada vez mais, principalmente nas áreas mais carentes (PLANTAMED, 2007). Esse aumento no uso de plantas medicinais requer padronizar os seus extratos e executar experimentos de toxicidade para garantir segurança no uso (ANVISA, 2006; PAIXÃO, 2006).

\subsubsection{Princípios ativos nas plantas medicinais}

"Planta medicinal é aquela que contém um ou mais de um princípio ativo que lhe confere atividade terapêutica" (MARTINS et al., 1992). O autor caracteriza as plantas medicinais entre as demais plantas, mas cabe ressaltar que muitas plantas ainda não consideradas como medicinais podem assumir tal status, após a realização de pesquisas científicas com o objetivo de identificar princípios ativos de natureza medicinal.

As plantas medicinais sintetizam compostos químicos a partir dos nutrientes, da água e da luz que recebem. Muitos desses compostos ou grupo deles podem provocar reações nos organismos: esses são os princípios ativos (CASAMADA, 1968; COSTA, 
2002; SIMÕES, 2001) Algumas dessas substâncias podem ser ou não tóxicas; isso depende, também, da dosagem em quem venham a ser utilizadas e também da forma de uso ou de preparação dos extratos.

De acordo com Martins (1992) existem vários grupos de princípios ativos; são eles: Alcaloides, Mucilagens, Flavonoides, Taninos e Óleos essenciais. Simões (2001) aponta Lipídios, Óleos voláteis, Polissacarídeos, Compostos Fenólicos Simples, Heterosídicos, Cumarinas, Cromonas, Xantonas, Lignanas, Neo-lignanas e seus análogos, Flavonoides, Taninos, Quinonas, Heterosídeos Cardioativos, Saponinas, Compostos com enxofre, Alcaloides (tropânicos, indólicos, Esteroides) e Metilxantinas.

Como estratégia para a investigação de plantas medicinais, as informações adquiridas junto às comunidades locais podem e devem ser combinadas com estudos químicos e farmacológicos de trabalhos científicos. O aproveitamento desses dados etnofarmacológicos é passo importante na sistematização do princípio ativo e também no desenvolvimento de pesquisas no âmbito da farmacologia desses extratos (SIMÕES, 2001).

\subsection{Abacate (Persea americana Mill)}

O abacate pertence à família Lauraceae, que compreende cerca de 50 gêneros diferentes, sendo Persea o subgênero do abacate. O abacate comercial é pertencente a duas espécies com três variedades: Mexicana (Persea americana var. drymifolia), Antilhana (Persea americana var. americana) e Guatemalense ou Guatemalteca (Persea nubigena var. guatemalensis) (SÁNCHEZ-PÉREZ, 2001).

Existem outros nomes populares para o abacate, em várias línguas. São eles: abacado, aguacate (esperanto, espanhol), avocado (inglês), zabelbok (francês), avvocato (italiano), entre outros (CONCEIÇÃO, 2000).

\subsubsection{Constituintes químicos}

O abacate é rico em potássio, cálcio, fósforo, ferro e possui quantidades variáveis de matéria insaponificável (máximo de $2 \%$ ). O fruto do abacate possui de $20 \%$ a 25\% de óleo, além de ácidos graxos, hidratos de carbono, substâncias minerais, ácido acético, ácido málico, carboidratos, asparagina, taninos, metil-eugenol, abacatina 
(princípio amargo), dopamina, quercetina, perseitol, proteínas, mucilagens, óleo essencial, flavonoides, estragol, anetol, hidrocarbonetos, ácidos voláteis, esteróis (sitosterol, campesterol), aminoácidos, vitaminas (A, B, D, E,) e lecitina (BROWN, 1972; GUTIERREZ, 1989; TESKE; TRENTINE, 1995).

Alonso (1998) descreve a composição considerando as partes da planta. A polpa do fruto apresenta ácido insaponificáveis (oleico, linoleico, cáprico, mirístico, esteárico) hidrocarbonetos alifáticos saturados, esqualeno, $\beta$-sitosterol, vitaminas A e E, ácido aspártico e glutâmico, fósforo, ferro, tiamina, riboflavina, niacina, ácido ascórbico. A semente (caroço) ácidos graxos e tocoferol, proantocianidina (biflavonil), hidrocarbonetos, derivados esteroides, glicídios e uma saponina. As folhas contêm óleos essenciais, estragol, metilchavicol, $\propto$-pineno, $\beta$-pineno, metileugenol, cineol, limoneno, quercetol, taninos e terpenos.

\subsubsection{Propriedades medicinais}

Dados etnofarmacológicos apontam que o abacate possui as seguintes propriedades: anti-inflamatória, antianêmica, antidiarréica, anti-helmíntica, antirreumática, antioxidante, antisséptica das vias respiratórias, antissifílica, antitênia, antiuricêmica, balsâmica, carminativa, cicatrizante, colagoga, colerética, depurativa, digestiva, diurética, emoliente, estomáquica, umectante, vermífuga e vulnerária. Com essas propriedades, a planta é usada popularmente em afecções hepáticas, doenças renais e vias urinárias, cistites, diarreias, disenterias, gases intestinais e estomacais, aftas, distúrbios das vias urinárias, para regularizar o fluxo menstrual e liberar a menstruação, ação esta atribuída aos flavonoides. O óleo tem grande riqueza de vitaminas e de grande utilidade no combate ao raquitismo (ALMEIDA, 1993; ALONSO, 1998; CONCEIÇÃO, 2000; LORENZI, 2002; TESKE; TRENTINE, 1995).

O óleo fixo do abacate é utilizado na medicina dermatológica com finalidades cosméticas e a industrialização do fruto para extração desse componente tem ocorrido (TANGO, 2006; TURATTI et al., 2002).

Dada à relevância do consumo de abacate em dietas de determinados países, incluindo o Brasil, estudos foram feitos, especialmente no México, relatando o papel protetor que os componentes do abacate possuem tanto na prevenção como no tratamento de cardiopatias. Em 1992, foi publicada a primeira evidência científica sobre 
SILVA, G. R. da; MEYER, T. N.; PEREIRA, J. B. B. Efeitos do extrato do caroço do abacate sobre a inflamação induzida na pata de ratos pela carragenina

a eficácia do abacate como fonte de ácidos graxos monoinsaturados (ácido oleico) em pessoas saudáveis, em substituição de gorduras saturadas, exercendo efeitos benéficos, reduzindo os níveis de colesterol total, de triglicerídeos e de LDL-colesterol (REBOLLO et al., 1998; TURATTI et al., 2002).

Em 1997, foi constatado em pacientes com hipercolesterolemia que, além do consumo do fruto reduzir o LDL, ele favorece o aumento do HDL-colesterol. Após o período de uma semana já ocorrem alterações sensíveis nos indicadores lipídicos do sangue. Além disso, já foi identificado que o consumo do abacate influencia também na glicemia. Após quatro semanas consumindo dieta contendo abacate, mulheres diabéticas insulino-dependentes, sem complicações graves decorrentes da doença, tiveram redução tanto no colesterol total sérico como na glicemia (LEDESMA et al., 1996).

Estudos comprovando os benefícios do consumo do fruto em longo prazo ainda são requeridos no sentido de reforçar seu papel terapêutico acima mencionado (SOARES, 2000; THOMSEN, 1999; WILLIAMS; KRAUSS, 1999).

O $\beta$-sitosterol presente no abacate também possuiria um efeito especial sobre a imunidade, podendo auxiliar no tratamento de doenças como o câncer, HIV e infecções. Notou-se que ele age aumentando a proliferação de linfócitos no corpo e a atividade das células NK (natural killers), que agem matando microrganismos invasores. No câncer, ele agiria suprimindo a carcinogênese, de acordo com alguns estudos realizados nesse sentido (ALMEIDA, 1993).

O abacateiro foi incluído na lista de plantas para o Programa de Pesquisa de Plantas Medicinais da Central de Medicamentos (PPPM) do Ministério da Saúde. Consta que as informações etnofarmacológicas que foram consideradas nessa etapa das pesquisas apenas avaliaram o efeito diurético das folhas. O uso do caroço nas comunidades é bastante comum e esse dado não foi abordado no Programa PPPM. Com o crescimento do uso de plantas medicinais esse aspecto carece de uma avaliação científica (BRASIL, 2006a; BRASIL, 2006b). De forma tradicional, as folhas do abacateiro são utilizadas pelas comunidades e constam da Farmacopeia Brasileira de 1959 (BRASIL, 1959).

\subsubsection{Caroço do abacate}


O caroço do abacate corresponde a cerca de um terço da massa total do fruto. Há interesse em caracterizá-lo, visando futuros estudos sobre o aproveitamento desse volumoso subproduto. A principal dificuldade na utilização do caroço de abacate é a presença de substâncias fenólicas, que apresentam toxicidade para animais monogástricos. Ichimaru et al. (1982) demonstraram que, pela extração dessas substâncias com etanol, os caroços poderiam ser usados na alimentação dos animais monogástricos.

Segundo Vieira (1992) e Lorenzi (2002) o caroço do abacate pode ter uma utilidade medicinal, particularmente no âmbito da ação anti-inflamatória, o que poderia incrementar seu cultivo e comercialização, confirmando sua importância dentre as plantas medicinais do Brasil.

\subsection{O edema de pata no estudo da reação inflamatória}

O edema de pata de ratos, provocado pela carragenina, é uma técnica usual nas pesquisas da ação anti-inflamatória. A carragenina é uma substância indutora de inflamação e muito utilizada nos experimentos que avaliam a ação anti-inflamatória (BARROS, 2004; CAPÓ, 2002). Henriques (1993) e Brasileiro (1998) abordam a reação inflamatória induzida por carragenina em ratos e apontam um edema desenvolvido nas primeiras horas, que pode ser utilizado como referencial para comparar a ação edematogênica ou antiedematogênica em testes laboratoriais. Segundo Sartori et al. (2003), a carragenina desencadeia o processo inflamatório mediado por prostaglandinas, sendo que o pico máximo se dá após duas a três horas da aplicação.

Segundo Barros (2004), o processo se desencadeia em três etapas. Na primeira hora após a injeção de carragenina há o aumento da permeabilidade vascular mediada por histamina e serotonina. Na segunda hora a permeabilidade é mediada por cininas. Três horas após a injeção ocorre a maior intensidade do edema, desencadeada por ação de prostaglandinas sobre a permeabilidade capilar. Medeiros et al. (2007) observaram que há liberação de histamina, bradicinina e 5-hidroxitriptamina durante a fase inicial do processo inflamatório.

Essa técnica permite avaliar de forma prática o volume do edema e caracterizar o efeito antiedematoso do extrato vegetal em estudo e, com isto, associar dados científicos para a elucidação do mecanismo de ação do extrato. Além disso, o método permite a 
SILVA, G. R. da; MEYER, T. N.; PEREIRA, J. B. B. Efeitos do extrato do caroço do abacate sobre a inflamação induzida na pata de ratos pela carragenina

observação do efeito sistêmico da substância teste através da indução de um estímulo inflamatório local (VAJJA et al., 2004).

\section{MÉTODO}

\subsection{Identificação da espécie vegetal}

A classificação da espécie vegetal em estudo foi desenvolvida por Pereira (2007) com amostras floridas obtidas de um abacateiro da Fazenda Córrego Fino, no município de Três Corações, MG, situada em ponto geográfico localizado a $894 \mathrm{~m}$ de altitude, nas coordenadas S $21^{\circ} 41^{\prime} 02^{\prime}$ ' e WO 45 $18^{\prime}$ 24,6', geo-referenciadas por um GPS marca ETREX ${ }^{\circledR}$, no mês de junho de 2006, às 08h30min da manhã, em dia ensolarado. Após montada a exsicata, encaminhou-se a mesma para classificação. A espécie vegetal foi classificada como Persea americana Mill e registrada sob o número 21.059 no Herbário da Universidade Federal de Lavras.

\subsection{Obtenção do extrato fluido}

Seguindo a técnica de Pereira (2007), utilizaram-se frutos maduros, colhidos no mês de junho de 2006, armazenados em armário fechado e enrolados em jornal, à temperatura ambiente. $\mathrm{O}$ amadurecimento foi percebido pelo toque das mãos e a percepção de amaciamento. A semente foi retirada, descorticada e triturada em ralo doméstico, na parte mais grossa, constituindo a droga vegetal.

Os extratos fluidos dessa droga vegetal foram obtidos pelo processo descrito na Farmacopeia dos Estados Unidos do Brasil (1959), com produto final na relação 1:1: o líquido extrator se constituiu de uma mistura hidroetanólica a 80\%. Pesaram-se 50 g do caroço de abacate ralado em uma balança Mettler Toledo® AB 204-S. Procedeu-se à percolação lenta em ampola de decantação de vidro (FIG. 1), na velocidade de gotejamento de 15 a 20 gotas / minuto. Recolheram-se os primeiros $37,5 \mathrm{~mL}$ de percolado para compor a solução-mãe, correspondendo a $75 \%$ do volume final do extrato a ser preparado. Esta solução-mãe foi mantida em geladeira. A percolação prosseguiu até que o percolado apresentasse cor próxima à do líquido extrator, conforme técnica desenvolvida por Pereira et al. (2007). 
Este percolado foi submetido a rotaevaporação em um evaporador rotativo Q3441/2 Quimis®, à temperatura de $40{ }^{\circ} \mathrm{C}$. O produto foi levado a estufa de circulação forçada microprocessada Q-314M Quimis ${ }^{\circledR}$, em cápsula de porcelana, para redução de volume até $12,5 \mathrm{~mL}$. A seguir foi adicionado à solução-mãe, completando $50 \mathrm{~mL}$ de extrato.

Ao extrato obtido com solução hidroetanólica a $80 \%$ denominou-se Extrato 80. Os extratos foram armazenados em frascos opacos, bem fechados, ao abrigo da luz, em geladeira. As características físico-químicas deste extrato estão na TAB. 1, na seção Resultados.

\subsection{Experimentos em animais}

Foram utilizados 25 ratos Wistar adultos, machos, com cerca de dois meses de idade e peso corporal de cerca de $340 \mathrm{~g}$. Os mesmos foram divididos aleatoriamente em cinco grupos de cinco animais cada. Foram mantidos no biotério da UNINCOR, em ciclos claro-escuro naturais, a temperatura ambiente, em gaiolas individuais, alimentados por ração industrial e água de torneira ad libitum.

Todos os animais foram submetidos a um período de jejum de água e de comida por 16 horas antes do início dos experimentos. Em todos os animais, a injeção de carregenina foi feita na almofada plantar da pata direita, usando-se seringa descartável de $1 \mathrm{~mL}$ e agulha de insulina, como se vê na FIG. 1.

Figura 1 - Injeção de carragenina na almofada plantar da pata traseira direita

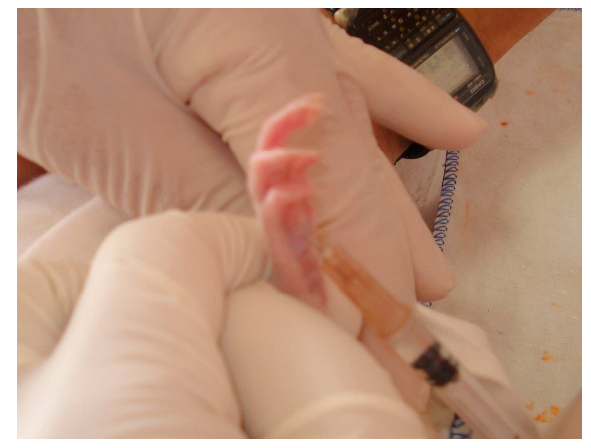

Fonte: Arquivo da pesquisa. 
SILVA, G. R. da; MEYER, T. N.; PEREIRA, J. B. B. Efeitos do extrato do caroço do abacate sobre a inflamação induzida na pata de ratos pela carragenina

Foram utilizados os seguintes tratamentos:

Grupo 1 - os animais receberam por via oral (gavagem) a dose de $1 \mathrm{~mL} / \mathrm{kg}$ de solução de cloreto de sódio a 0,9\%. Após 30 minutos, foi injetado, na região plantar da pata traseira direita de cada rato, $0,1 \mathrm{~mL}$ de carragenina por via subcutânea.

Grupo 2 - os animais receberam por via oral (gavagem) a dose de $40 \mathrm{mg} / \mathrm{kg}$ de uma solução de $40 \mathrm{mg} / \mathrm{mL}$ de piroxicam . Após 30 minutos, foi injetado, na região plantar da pata traseira direita de cada rato, $0,1 \mathrm{~mL}$ de carragenina por via subcutânea.

Grupo 3 - os animais receberam por via oral (gavagem) a dose de 0,5 mL / kg do extrato hidroalcóolico de semente de abacate. Após 30 minutos, foi injetado, na região plantar da pata traseira direita de cada rato, $0,1 \mathrm{~mL}$ de carragenina por via subcutânea.

Grupo 4 - os animais receberam por via oral (gavagem) a dose de 1,5 mL / kg do extrato hidroalcóolico de semente de abacate. Após 30 minutos, foi injetado, na região plantar da pata traseira direita de cada rato, $0,1 \mathrm{~mL}$ de carragenina por via subcutânea.

Grupo 5 - os animais receberam por via oral (gavagem) a dose de 2,0 mL / kg do extrato hidroalcóolico de semente de abacate. Após 30 minutos, foi injetado, na região plantar da pata traseira direita de cada rato, $0,1 \mathrm{~mL}$ de carragenina por via subcutânea.

Em todos os grupos, o volume da pata traseira direita e esquerda (que não recebeu injeção de carragenina) de cada animal foi medido logo após a administração das substâncias $(0 \mathrm{~h})$, repetindo-se mais quatro medições com intervalos de uma hora entre cada uma ( 1 h, 2 h, 3 h, e 4 h). As medições foram feitas por uma variação do sistema em que se utiliza um pletismômetro (WINTER; RISLEY; NUSS, 1962).

O pletismômetro foi substituído por um sistema simplificado. Em um suporte de metal, fixou-se uma seringa plástica de $10 \mathrm{~mL}$ com sua extremidade cortada e contendo água até uma altura determinada.

A pata do rato foi imersa no líquido no interior da seringa até que o limite superior do maléolo lateral coincidisse com a borda da seringa (FIG. 2). 
Figura 2 - Imersão da pata do rato até a marca no limite superior do maléolo lateral
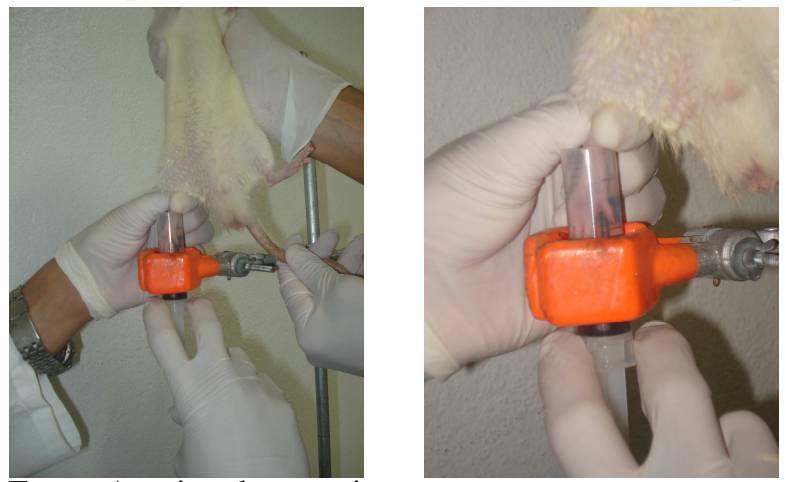

Fonte: Arquivo da pesquisa.

Após a imersão, o êmbolo da seringa foi propelido superiormente, até a água atingir a borda da mesma. O volume da pata foi calculado retirando-se cuidadosamente a mesma e completando-se o interior da seringa, com pipeta graduada, até que, novamente, a água atingisse o seu bordo superior. A quantidade de água necessária para completar a seringa correspondeu ao volume da porção imersa da pata do animal.

Os animais foram mortos por transecção medular após os experimentos.

Os resultados foram tabulados e analisados. Foram calculadas as médias dos valores de cada um dos cinco grupos. Foram comparados os volumes das patas dos animais no início e no final dos experimentos, sendo calculados os incrementos de volume, em percentual, desde o início até o final. Os resultados foram submetidos à análise estatística (Programa SANEST), utilizando-se análise de variância e o teste de Tukey para a comparação das médias.

\section{RESULTADOS}

A carragenina foi eficaz na indução do processo inflamatório, como se pode ver na TAB. 2 e na FIG. 3, as quais também mostram que nenhum dos tratamentos foi eficaz na redução do edema, pois não ocorreram diferenças significativas entre os tratamentos. 
SILVA, G. R. da; MEYER, T. N.; PEREIRA, J. B. B. Efeitos do extrato do caroço do abacate sobre a inflamação induzida na pata de ratos pela carragenina

Tabela 1 - Características físico-químicas do extrato hidroetanólico de caroço de abacate

\begin{tabular}{lc}
\multicolumn{2}{c}{ (Persea americana Mill). } \\
\hline Determinações fisico-químicas & Extrato 80 \\
\hline Cor & Castanho avermelhado \\
Odor & Agradável \\
Resíduo seco & $3,8 \%$ \\
Cinzas totais & $4,2 \%$ \\
$\mathrm{pH}$ & 6,28 \\
Densidade & 0,9152 \\
\hline
\end{tabular}

Fonte: Dados da pesquisa.

Tabela 2 - Volume da pata ao longo do período experimental em função da aplicação de carragenina (pata D) ou não (pata $\mathrm{E}$ ) e do uso de piroxicam $(\mathrm{G} 2)$, ou do extrato hidroalcoólico do caroço de abacate (G3, G4 e G5)

\begin{tabular}{cccccccccccc}
\hline & \multicolumn{3}{c}{$0 h$} & \multicolumn{3}{c}{$l h$} & \multicolumn{3}{c}{$2 h$} & \multicolumn{3}{c}{$3 h$} & \multicolumn{2}{c}{$4 h$} \\
\cline { 2 - 11 } Grupo & Pata & Pata & Pata & Pata & Pata & Pata & Pata & Pata & Pata & Pata \\
& $\begin{array}{c}\text { D } \\
(\mathrm{mL})\end{array}$ & $\begin{array}{c}\mathrm{E} \\
(\mathrm{mL})\end{array}$ & $\begin{array}{c}\mathrm{D} \\
(\mathrm{mL})\end{array}$ & $\begin{array}{c}\mathrm{E} \\
(\mathrm{mL})\end{array}$ & $\begin{array}{c}\mathrm{D} \\
(\mathrm{mL})\end{array}$ & $\begin{array}{c}\text { E } \\
(\mathrm{mL})\end{array}$ & $\begin{array}{c}\mathrm{D} \\
(\mathrm{mL})\end{array}$ & $\begin{array}{c}\text { E } \\
(\mathrm{mL})\end{array}$ & $\begin{array}{c}\text { D } \\
(\mathrm{mL})\end{array}$ & $\begin{array}{c}\text { E } \\
(\mathrm{mL})\end{array}$ \\
\hline G1 & 1,61 & 1,39 & 1,66 & 1,46 & 1,74 & 1,48 & 1,78 & 1,58 & 1,73 & 1,57 \\
G2 & 1,56 & 1,47 & 1,70 & 1,51 & 1,72 & 1,42 & 1,74 & 1,60 & 1,77 & 1,54 \\
G3 & 1,37 & 1,47 & 1,52 & 1,47 & 1,63 & 1,47 & 1,71 & 1,47 & 1,64 & 1,47 \\
G4 & 1,47 & 1,19 & 1,68 & 1,33 & 1,75 & 1,41 & 1,88 & 1,7 & 1,84 & 1,48 \\
G5 & 1,52 & 1,39 & 1,74 & 1,47 & 1,94 & 1,52 & 1,97 & 1,76 & 1,74 & 1,55 \\
\hline
\end{tabular}

Fonte: Dados da pesquisa.

Figura 3 - Volume da pata ao final do período experimental em função da aplicação de carragenina (pata direita) ou não (pata esquerda) e do uso de piroxicam (G2) ou do extrato hidroalcóolico do caroço de abacate (G3, G4 e G5)

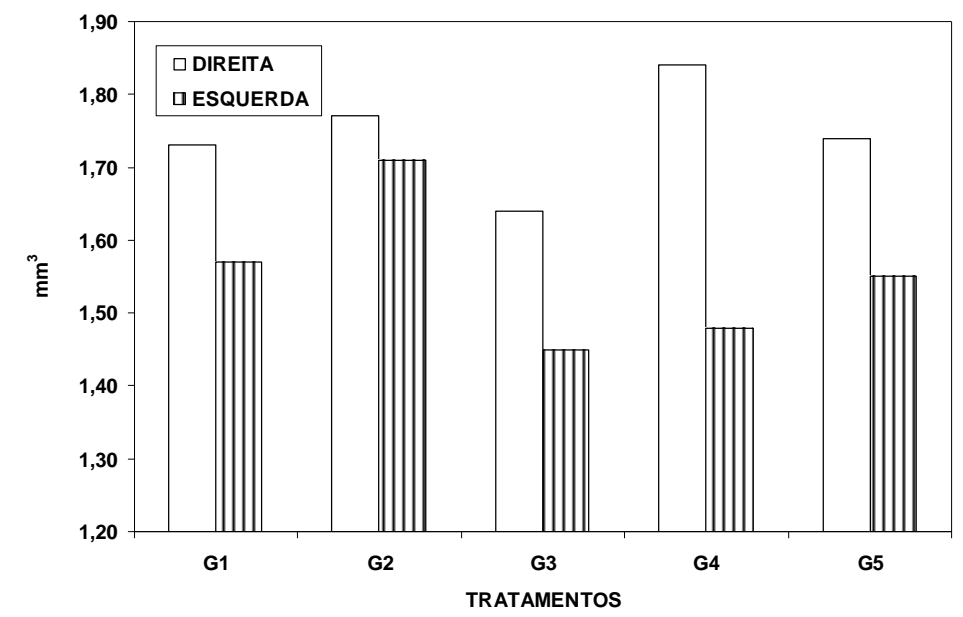

Fonte: Arquivo da pesquisa. 
Na FIG. 4 podem ser vistos os resultados da evolução do volume da pata direita dos animais, em todos os grupos experimentais, desde o período zero até a última medição (4 horas após o início dos experimentos). Não foram constatados efeitos significativos de redução do edema com o uso do piroxicam e nem com a utilização dos extratos de caroço de abacate.

Figura 4 - Evolução do volume da pata direita dos ratos, ao longo do período experimental, nos cinco grupos.

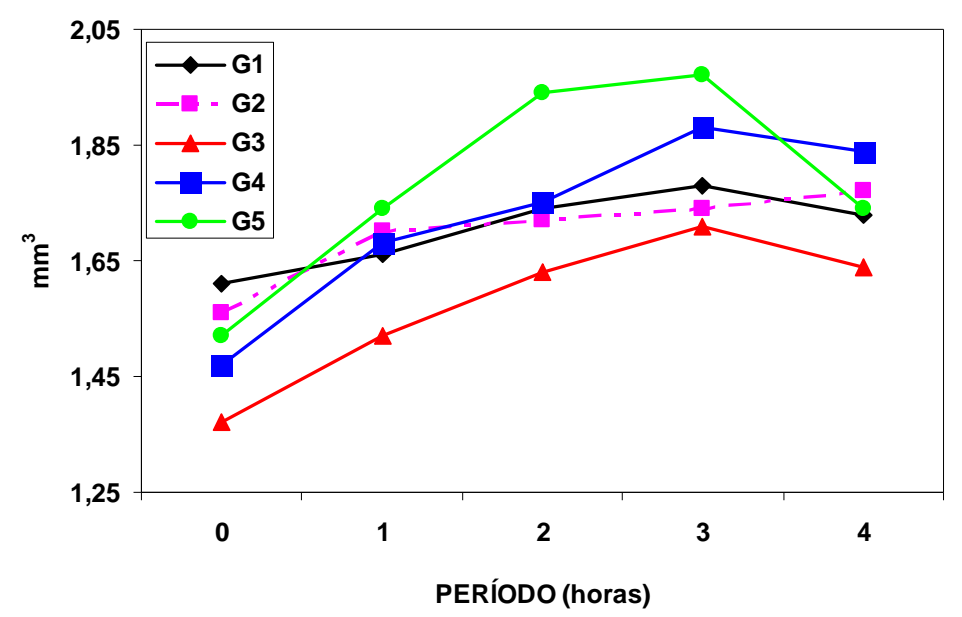

Fonte: Arquivo da pesquisa.

A TAB. 3 exibe os volumes médios das patas direitas dos animais, em todos os grupos experimentais, no período de $4 \mathrm{~h}$ (final). Não foram encontradas diferenças significativas entre os grupos.

Na TAB. 4 verifica-se o ocorrido com o aumento de volume da pata direita dos animais, em percentual, comparando-se o período zero com o final dos experimentos, em todos os grupos. Não houve redução estatisticamente significativa do edema nos grupos 2 a 5 , se comparados com o grupo 1 . 
Tabela 3 - Valores médios (mL) obtidos ao final do período experimental para a variação do volume da pata direita dos ratos submetidos a diferentes tratamentos

\begin{tabular}{c|c}
\hline GRUPOS DE & $\begin{array}{c}\text { MEDLAS DOS } \\
\text { VOLUMES DAS } \\
\text { PATAAMS }(\mathbf{m L})\end{array}$ \\
\hline G1 & 1,70 \\
G2 & 1,69 \\
G3 & 1,57 \\
G4 & 1,72 \\
G5 & 1,78 \\
\hline
\end{tabular}

Fonte: Dados da pesquisa.

Tabela 4 - Variação percentual da média do volume da pata direita de ratos ao final do período experimental, em relação ao início dos experimentos

\begin{tabular}{c|c}
\hline $\begin{array}{c}\text { GRUPOS DE } \\
\text { TRATAMENTOS }\end{array}$ & $\begin{array}{c}\text { Variação do volume } \\
\text { da pata de rato (\%) }\end{array}$ \\
\hline G1 & 7,45 \\
G2 & 13,46 \\
G3 & 19,71 \\
G4 & 25,17 \\
G5 & 14,47 \\
\hline
\end{tabular}

Fonte: Dados da pesquisa.

\section{DISCUSSÃO}

O uso etnofarmacológico de derivados de plantas é prática generalizada entre a população. Entretanto, o mero relato de determinados efeitos não significa que tais ações de fato existam, requerendo pesquisas científicas que possam comprovar ou negar o que é popularmente propalado. Esse pensamento motivou a realização do presente trabalho, no qual se pesquisaram possíveis efeitos anti-inflamatórios do extrato do caroço do abacate.

Henriques (1993) utilizou o modelo de inflamação induzida pela carragenina na pata de ratos como referencial para comparar a ação edematogênica ou 
antiedematogênica, isto é, inflamatória ou anti-inflamatória, em estudos in vivo. $\mathrm{O}$ modelo foi adotado no presente trabalho, por ser consagrado na literatura e não ter execução laboriosa ou dispendiosa. Entretanto, a indisponibilidade de um pletismômetro forçou-nos a usar uma técnica alternativa, simplificada e de baixo custo. É possível que a sensibilidade dessa adaptação seja menor do que aquela do pletismômetro. Estudos ulteriores poderão investigar melhor esse aspecto. De todo modo, em um país em que as verbas para pesquisa não estão prontamente acessíveis em todos os lugares, a busca por alternativas de menor custo, como a que usamos, pode ser útil na atividade científica. Os resultados obtidos mostraram indução de edema pela carragenina injetada na pata direita dos animais, de tal sorte que se pode afirmar que o modelo funcionou corretamente.

Os resultados não mostraram atividade anti-inflamatória no modelo utilizado, indo dessa forma contra o que os relatos etnofarmacológicos alegam. Em nenhum dos grupos em que se utilizou o extrato, em doses diferentes, houve redução do edema induzido pela carragenina. Na verdade, nos grupos 2 a 5 , os valores do volume da pata traseira foram maiores, em números absolutos, do que no grupo de controle. Até mesmo no grupo 2, em que se utilizou o piroxicam, não foi observada redução do edema, fato cuja explicação carece de maiores investigações.

Esses resultados corroboram àqueles constatados em outro trabalho da mesma linha de pesquisas da UNINCOR (RODRIGUES, 2008), no qual tampouco foram encontrados efeitos anti-inflamatórios do extrato do caroço do abacate em um modelo de peritonite induzida pela carragenina em ratos. Somam-se, portanto, evidências contra a alegada ação antiflogística deste produto vegetal.

\section{CONSIDERAÇÕES FINAIS}

Não foram constatados, no presente trabalho, efeitos anti-inflamatórios do extrato hidroalcóolico do caroço de abacate sobre o edema induzido pela carragenina na pata traseira de ratos.

\section{REFERÊNCIAS}


ABIF-Associação Brasileira das Indústrias Farmacêuticas. Disponível em: <http:www.achetudoeregiao.com.br/ANIMAIS/plantas_medicinais.htm> Acesso em: 18 set. 2007.

ALMEIDA, E. R. Plantas medicinais brasileiras: conhecimentos populares e científicos. São Paulo: Hemus, 1993.

ALONSO, J. R. Tratado de fitomedicina: bases clínicas e farmacológicas. Buenos Aires: Isis Ediciones, 1998.

ANVISA-Agência Nacional de Vigilância Sanitária. Resolução RDC n⿳0 088 de 16/03/2004. Determ ASIL. Ministério da Saúdeina a publicação da lista de referências bibliográficas para avaliação de segurança e eficácia de fitoterápicos. Disponível em: <http://e-legis.anvisa.gov.br>. Acesso em: 08 mar. 2006.

ANVISA-Agência Nacional de Vigilância Sanitária. Resolução RE n⿳0 090 de 16/03/2004. Determina a publicação do Guia para realização de estudos de toxicidade pré-clínica de fitoterápicos. Disponível em: <http://e-legis.anvisa.gov.br>. Acesso em: 08 mar. 2006.

BARROS, F. E. V. et al. Avaliação das atividades analgésica e antinflamatória do extrato metanólico de Calotropis Procera R. BR. (ciúme). Infarma, Brasília, v. 16, n. 9-10, p. 60-64, 2004.

BRASILEIRO FILHO, G. B. Patología geral. 2. ed. Rio de Janeiro: Guanabara Koogan, 1998.

BRASIL. Farmacopéia dos Estados Unidos do Brasil. 2. ed. São Paulo: Industria Gráfica Siqueira, 1959.

Farmacopéia dos Estados Unidos do Brasil: parte 2. 4. ed. São Paulo: Atheneu, 2000.

Ministério da Saúde. Secretaria de Ciência, Tecnologia e Insumos Estratégicos. Departamento de Assistência Farmacêutica. A fitoterapia no SUS e o programa de pesquisas de plantas medicinais da central de medicamentos. Brasília, 2006a.

2006b.

Política nacional de plantas medicinais e fitoterápicos. Brasília,

BROWN, B. I. Isolation of unpleasant flavor compounds in the avocado (Persea Americana). Journal of Agricultural and Food Chemistry, Washington, DC, v. 20, n. 4, 1972.

CAPÓ, J. I. et all. Atividad antiinflamatória de extractos de derivados de la caña de azúcar. Revista Cubana de Plantas Medicinales, Havana, v. 2002, n. 2, ago. 2002. Disponível em: <http:www.scielo.sld.cu/scielo.php?pid=S1028$47962002000200004 \&$ script=sciarttext $>$ Acesso em: 12 mar. 2007. 
SILVA, G. R. da; MEYER, T. N.; PEREIRA, J. B. B. Efeitos do extrato do caroço do abacate sobre a inflamação induzida na pata de ratos pela carragenina

CASAMADA, R. S. M. Farmacognosia con farmacodinamia. Barcelona: Editorial Científico-Médica, 1968.

CONCEIÇÃO, M. As plantas medicinais do ano 2000. 2. ed. São Paulo: Tão Editora, 2000 .

CORREA, J. R. C.; MING, L. C.; SCHEFFER, M. C. Cultivo de plantas medicinais, condimentares e aromáticas. Curitiba: EMATER-PR, 1991.

COSTA, A. F. Farmacognosia. 6. ed. Portugal: Fundação Calouste Gulbenkian, 2002.

DI STASI, L. C. et al. Plantas medicinais: arte e ciência, um guia de estudo interdisciplinar. São Paulo: Ed UNESP, 1996.

GEISSMAN, T. A.; DITTMAR, H. F. K. A proanthocyanidin from avocado seed. Phytochemistry, v. 4, p. 359-368, 1965.

GOLDENBERG, J. Coluna ponto e vírgula: colocando um ponto final nas dúvidas, colocando vírgulas nos mitos. 5. ed. São Paulo: Atheneu, 2005.

GUIMARÃES, M. L. S. História e natureza em Von Martius: esquadrinhando o Brasil para construir a nação. História, Ciências, Saúde - Manguinhos, Rio de Janeiro, v. 8, n. 2, p. 389-410, jul./out. 2000.

GUTIERREZ, M. A.; OLIVEIRA, F. Caracterização farmacognóstica da droga e do extrato fluido de Persea americana Mill. Revista Brasileira de Farmacognosia, Curitiba, v. 2, n. 4, p. 29-44, 1987/1989.

HENRIQUES, M. G. Estudo da reação inflamatória induzida por carragenina em camundongos. 1993. 181 f. Tese (Doutorado em Farmacologia)-Fundação Oswaldo Cruz, Departamento de Fisiologia e Farmacodinâmica, Rio de Janeiro, 1993.

ICHIMARU, D. L.; SALES, A. M.; IADEROZA, M.; BALDINI, V. L. S. Estudo dos fatores antinutricionais do caroço de abacate (Persea americana Mill. cv. Wagner). Coletânea do ITAL, Campinas, v. 12, p. 67-83, 1982.

LEDESMA, R. L. et al. Monounsatureted fatty acid (avocado) rich diet for mild hypercholesterolemia. Archives of Medical Research, USA, v. 27, p. 519-523, 1996.

LIMA, V. Ginástica laboral: atividade física no ambiente de trabalho. 2. ed. São Paulo: Phorte, 2005.

LORENZI, H.; MATOS, F. J. A. Plantas medicinais no Brasil: nativas e exóticas. São Paulo: Instituto Plantarum, 2002.

MARTINS, E. R.; MITSUGUI, S. Y.; SILVIA, A. V. Plantas medicinais: da colheita a comercialização. Viçosa: UFV/ Depto. de Fitotecnia, 1992. (datilografado). 
SILVA, G. R. da; MEYER, T. N.; PEREIRA, J. B. B. Efeitos do extrato do caroço do abacate sobre a inflamação induzida na pata de ratos pela carragenina

MEDEIROS, K. C. P. Effect of the activity of the Brazilian polyherbal formulation: eucalyptus globulus Labill, Peltodon radicans Pohl and Schinus terebinthifolius Radd in infl ammatory models. Revista Brasileira de Farmacognosia, Curitiba, 2007.

PAIXÃO, G. C. Avaliação da toxicidade pré-clínica do extrato alcoólico das flores da Pyrostegia venusta (Ker.) Miers em ratos Wistar. 2006. 86 f. Dissertação (Mestrado em Biotecnologia)-Universidade Vale do Rio Verde, Três Corações, 2006.

PEREIRA, J. B. B.; REZENDE, L. V. Caracterização de extratos hidroetanólicos de semente de Persea Americana M. (abacateiro). Monografia. Universidade Federal de Alfenas, Alfenas, 2007.

PLANTAMED. Plantas medicinais e aromáticas. Disponível em:

<http://www.herbario.com.br/atual03/2311plantmed.htm> Acesso em: 17 set. 2007.

REBOLLO, A. J. G. et al. Effects of comsumption of meat product rich in monounsaturated fatty acids (the ham from the Iberian pig) on plasma lipids. Nutrition Research, Tarrytown, v. 18, p. 743-750, 1998.

RIO DE JANEIRO. Secretaria Municipal de Saúde. Memento terapêutico de fitoterápicos. Rio de Janeiro, 2002.

RODRIGUES, L .C. C. Avaliação da atividade antiinflamatória do extrato hidroalcoólico do caroço do abacate sobre a peritonite induzida pela carragenina em ratos. 2008. 37 f. Dissertação (Mestrado em Biotecnologia)-Universidade Vale do Rio Verde, Três Corações, 2008.

SÁNCHEZ-PÉREZ, J. de la L. Recursos genéticos de aguacate en México. In: CONGRESO MEXICANO Y LATINOAMERICANO DEL AGUACATE, 1., 2001, Uruapan. Anales del... Uruapan, Mexico, 2001.

SIMÕES, C. M. O. et al. Farmacognosia: da planta ao medicamento. 3. ed. rev. Porto Alegre: EFRGS, 2001.

SOARES, H. F. O ácido graxo monoinsaturado do abacate no controle das dislipidemias. Revista de Ciências Médicas, Campinas, v. 9, p. 47-51, 2000.

TANGO, J. S. et al. Caracterização física e química de frutos de abacate visando a seu potencial para extração de óleos. Revista Brasileira de Fruticultura, Jaboticabal, v. 26, n. 1, p. 17-23, abr. 2004. Disponível em: 〈htpp:www.scielo.br/scielo.php?pid=>. Acesso em: 27 abr. 2006.

TESKE, M.; TRENTINI, A. M. Compêndio de fitoterapia. 2. ed. rev. ampl. Curitiba: Herbarium Laboratório Botânico, 1995.

THOMSEN, C. et al. Differential effects of satured and monounsaturede fatty acids on postprandial lipidemia and incretin responses in healthy subjects. American Journal of Clinical Nutrition, USA, v. 69, p. 1135-1143, 1999. 
TURATTI, J. M.; GOMES, R. A. R.; ATHIÉ, I. Lipídeos: aspectos funcionais e novas tendências. Campinas: ITAL, 2002.

VAJJA, B. N. L.; JULURI, S.; KUMARI, M.; KOLE, L.; CHAKRABARTI, R.; JOSHI, V. D. Lipopolysaccharide-induced paw edema model for detection of cytokine modulating anti-inflammatory agents. International Immunopharmacology, USA, v. 4, p. 901-909, 2004.

VIEIRA, L. S. Fitoterapia da Amazônia: manual de plantas medicinais, a farmácia de Deus. 2. ed. rev. São Paulo: Editora Agronômica Ceres, 1992.

WILLIAMS, T.; KRAUSS, R. M. Low-fat diets, lipoproteins subclasses, and heart disease risk. American Journal of Clinical Nutrition, USA, v. 70, p. 949-950, 1999. Disponível em: 〈http:www.ajcn.org/cgi/reprint/70/6/949.pdf >. Acesso em: 02 set. 2007.

WINTER, C. A.; RISLEY, E. A.; NUSS, G. W. Carrageenin-induced oedema in hind paw of the rat as a essay for antiinflammatory drugs. Proceedings of the Society for Experimental Biology and Medicine, USA, v. 111, n. 1, p. 543-547, 1962.

WHO-World Health Organization. Constitution of the World Health Organization. Basic Documents. Genebra, 1946. 